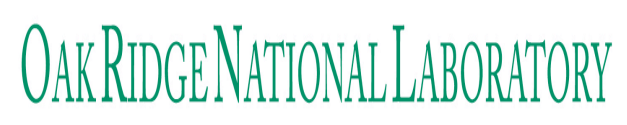

managed by Utbattelle For the departMeNt of energy

\section{Technical Project Plan \\ for}

The Enhanced Thermal Conductivity of

Oxide Fuels Through the Addition of

High Thermal Conductivity Fibers and

Microstructural Engineering

Revision 0

September 2010

Prepared for the

United States Department of Energy -

Office of Nuclear Energy under the

Fuel Cycle Research and Development Program -

Advanced Fuels Campaign 


\section{DOCUMENT AVAILABILITY}

Reports produced after January 1, 1996, are generally available free via the U.S. Department of Energy (DOE) Information Bridge.

Web site http://www.osti.gov/bridge

Reports produced before January 1, 1996, may be purchased by members of the public from the following source.

National Technical Information Service 5285 Port Royal Road

Springfield, VA 22161

Telephone 703-605-6000 (1-800-553-6847)

TDD 703-487-4639

Fax 703-605-6900

E-mailinfo@ntis.fedworld.gov

Web site http://www.ntis.gov/support/ordernowabout.htm

Reports are available to DOE employees, DOE contractors, Energy Technology Data Exchange (ETDE) representatives, and International Nuclear Information System (INIS) representatives from the following source.

Office of Scientific and Technical Information P.O. Box 62

Oak Ridge, TN 37831

Telephone 865-576-8401

Fax 865-576-5728

E-mail reports@adonis.osti.gov

Web site http://www.osti.gov/contact.html

This report was prepared as an account of work sponsored by an agency of the United States Government. Neither the United States Government nor any agency thereof, nor any of their employees, makes any warranty, express or implied, or assumes any legal liability or responsibility for the accuracy, completeness, or usefulness of any information, apparatus, product, or process disclosed, or represents that its use would not infringe privately owned rights. Reference herein to any specific commercial product, process, or service by trade name, trademark, manufacturer, or otherwise, does not necessarily constitute or imply its endorsement, recommendation, or favoring by the United States Government or any agency thereof. The views and opinions of authors expressed herein do not necessarily state or reflect those of the United States Government or any agency thereof. 


\title{
TECHNICAL PROJECT PLAN FOR \\ THE ENHANCED THERMAL CONDUCTIVITY OF OXIDE FUELS THROUGH THE ADDITION OF HIGH THERMAL CONDUCTIVITY FIBERS AND MICROSTRUCTURAL ENGINEERING
}

\author{
Prepared for the DOE-NE \\ Fuel Cycle Research and Development Program \\ Advanced Fuels Campaign
}

Plan Integrator - D. F. Hollenbach

D. F. Hollenbach, ${ }^{1}$ L. J. Ott, ${ }^{1}$ T. M. Besmann ${ }^{2}$, B. L. Armstrong ${ }^{2}$, A. A. Wereszczak ${ }^{2}$

H. T. Lin $^{2}$, R. J. Ellis ${ }^{1}$, P. F. Becher ${ }^{2}$, R. T. Jubin' ${ }^{2}$, and S. L. Voit ${ }^{2}$

${ }^{1}$ Nuclear Science and Technology Division

${ }^{2}$ Materials Science and Technology Division

September 2010

Prepared by the

OAK RIDGE NATIONAL LABORATORY

Oak Ridge, Tennessee 37831

Managed by

UT-Battelle, LLC

for the

U.S. Department of Energy

under contract DE-AC05-00OR22725 


\section{CONTENTS}

Page

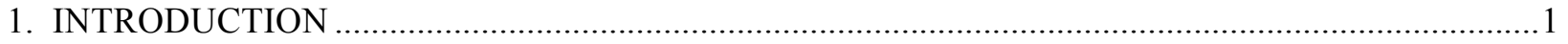

1.1 HIGH THERMAL CONDUCTIVITY FIBER BACKGROUND …............................................2

1.2 MICROSTRUCTURAL ENGINEERING BACKGROUND ......................................................

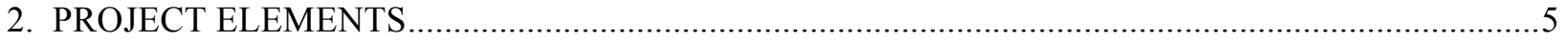

2.1 TASK 1 - HIGH THERMAL CONDUCTIVITY FIBER TASKS ...............................................

2.2 TASK 2 - MICROSCTRUCTURAL ENGINEERING TASKS ...............................................

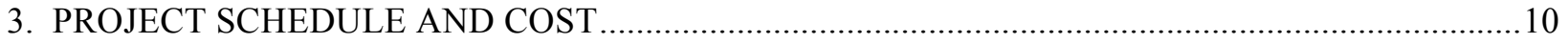




\section{EXECUTIVE SUMMARY}

The commercial nuclear power industry is investing heavily in advanced fuels that can produce higher power levels with a higher safety margin and be produced at low cost. Although chemically stable and inexpensive to manufacture, the in-core performance of $\mathrm{UO}_{2}$ fuel is limited by its low thermal conductivity. There will be enormous financial benefits to any utility that can exploit a new type of fuel that is chemically stable, has a high thermal conductivity, and is inexpensive to manufacture. At reactor operating temperatures, $\mathrm{UO}_{2}$ has a very low thermal conductivity $(<5 \mathrm{~W} / \mathrm{m} \cdot \mathrm{K})$, which decreases with temperature and fuel burnup. This low thermal conductivity limits the rate at which energy can be removed from the fuel, thus limiting the total integrated reactor power. If the fuel thermal conductivity could be increased, nuclear reactors would be able to operate at higher powers and larger safety margins thus decreasing the overall cost of electricity by increasing the power output from existing reactors and decreasing the number of new electrical generating plants needed to meet base load demand. The objective of the work defined herein is to produce an advanced nuclear fuel based on the current $\mathrm{UO}_{2}$ fuel with superior thermal conductivity and structural integrity that is suitable for current and future nuclear reactors, using the existing fuel fabrication infrastructure with minimal modifications.

There are two separate components to the research: (1) Enhanced Thermal Conductivity (ETC) - adding high conductivity fibers to the $\mathrm{UO}_{2}$ prior to sintering, which act as conduits for moving the heat energy generated within the pellet to the outer surface, (2) Microstructural Engineering (ME) - adding second phase particulates to $\mathrm{UO}_{2}$ bodies to retard grain growth and to increase thermal conductivity, as well as improve fracture and creep resistance. Different groups will perform the laboratory work for each of these research components with some overlap in personnel. The overlapping areas primarily involve computer simulations and final testing of the fuel in a reactor.

The estimated cost and duration of this project is $\$ 5,000,000$ over three years.

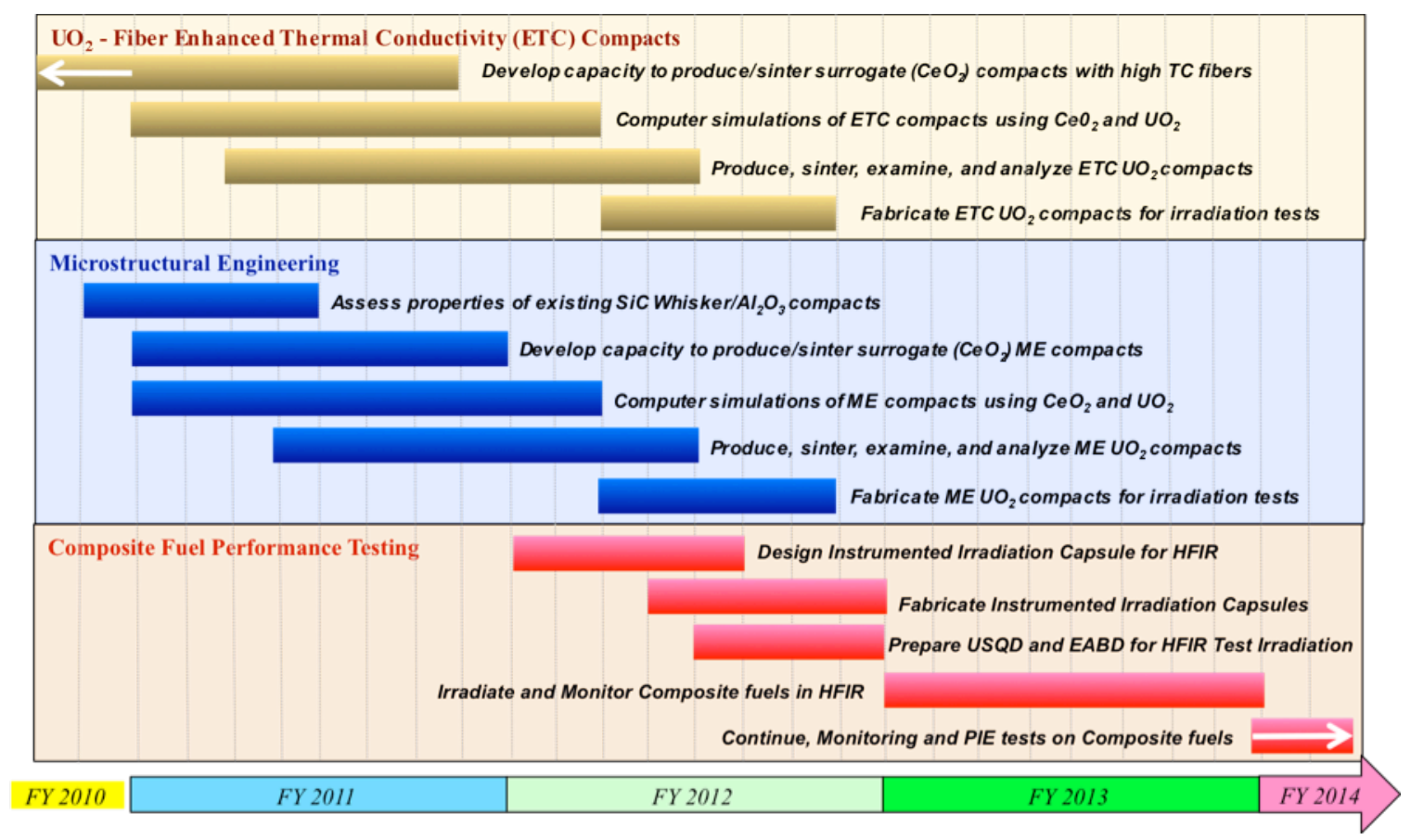

Fig. E-1. Flowchart of Proposed Work Schedule. 


\section{INTRODUCTION}

All current power reactors use $\mathrm{UO}_{2}$ as their fuel because it is relatively chemically inert and inexpensive to manufacture. The primary problem with $\mathrm{UO}_{2}$ fuel is that it has a very low thermal conductivity $(\sim 2.5$ $\mathrm{W} / \mathrm{m} \cdot \mathrm{K}$ at $1500 \mathrm{~K}$ for fresh fuel) that decreases as the fuel is burned, ${ }^{1}$ see Figure 1 . This limits the rate at which heat energy can be removed from the fuel and thus limits the rate of power generation within the fuel. NRC regulations specify the fuel temperatures must not exceed melting temperatures even under accident conditions. The higher the thermal conductivity, the lower the temperature difference between the fuel centerline temperature and fuel edge temperature thus decreasing the amount of stored heat energy in the fuel and increasing the safety margin. Figure 2 shows the radial temperature profile of a fuel rod as a function of fuel thermal conductivity. As shown, simply doubling the fuel thermal conductivity decreases the centerline temperature by over $400 \mathrm{~K}$ whereas increasing it by a factor of 5 drops the centerline temperature only another $300 \mathrm{~K}$ for a total difference of $700 \mathrm{~K}$. If the fuel thermal conductivity could be increased, the heat energy could more quickly be extracted from the fuel rod, resulting in cooler, more stable fuel, less fission gas release, and possibly higher total reactor power levels. Accident scenarios (such as Loss of Coolant Accidents) are analyzed assuming certain levels of stored energy in the fuel; since the fuel would be operating at much lower temperatures, the current restrictions imposed by these analyses would be extremely conservative and could be eased.

UO2 Fuel (95\%TD) Thermal Conductivity

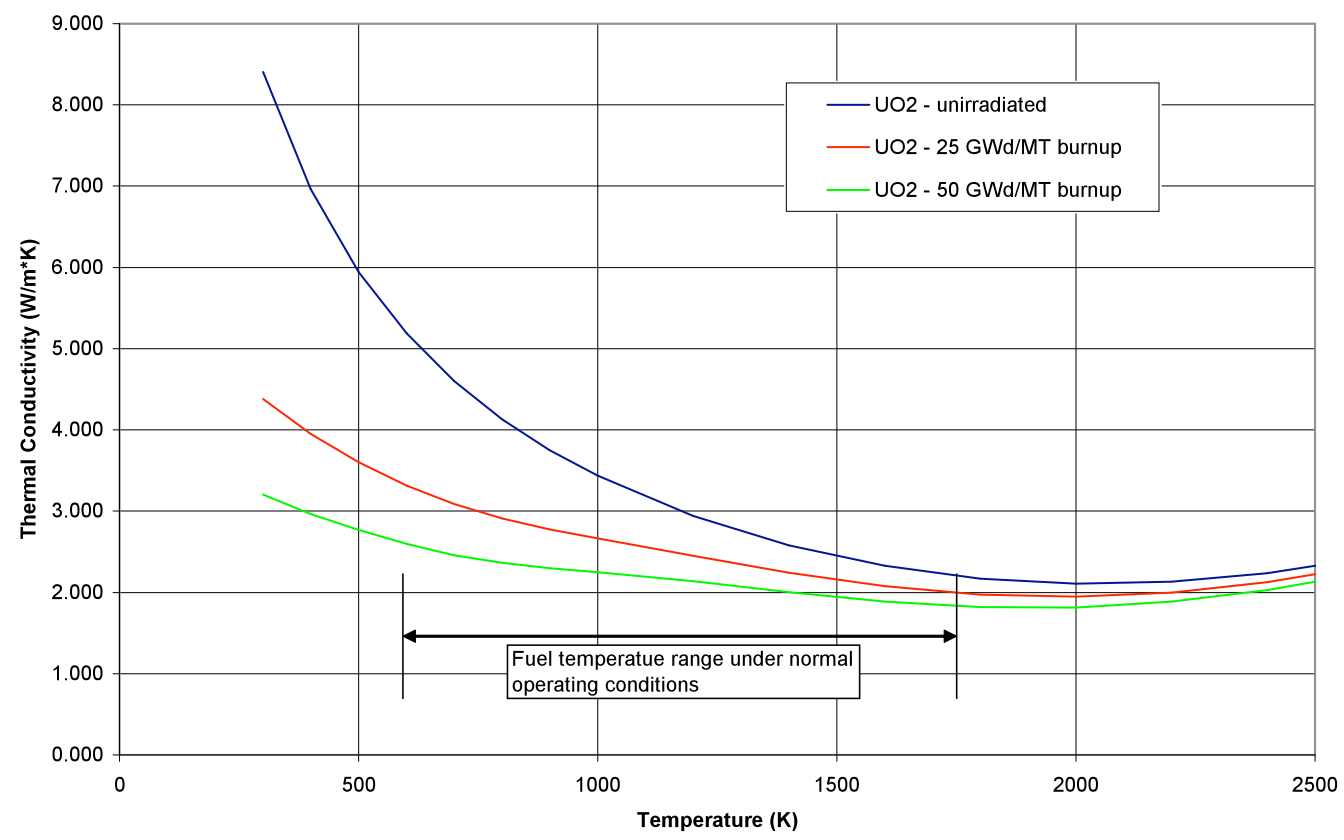

Fig. 1. $\mathrm{UO}_{2}$ fuel thermal conductivity as a function of temperature (K) for $\mathrm{UO}_{2}$ fuel at different burnups of gigawatt-days per metric ton of uranium (GWd/Mt).

Historically, ${ }^{2,3}$ several advanced nuclear fuels having higher thermal conductivities $(k)$ have been extensively studied. Different chemical compositions of uranium having higher material thermal conductivities were examined such as: uranium metal, uranium carbide (UC), and uranium nitride (UN). Although uranium metal has been successfully used in fast reactors using liquid sodium as a coolant, its suitability for use in water reactors is problematic since uranium metal reacts with water. UC and UN also have very high thermal conductivities $(>20 \mathrm{~W} / \mathrm{m} \cdot \mathrm{K})$ but are more expensive to manufacture and are 
chemically more reactive than $\mathrm{UO}_{2}$ with water at operating temperatures. Even given these limitations, $\mathrm{U}-$ metal, UC and UN are being examined as possible replacements for $\mathrm{UO}_{2}$ as the primary fuel in watercooled reactors because of their high thermal conductivities and mechanical stability as the fuel is burned. A different approach to creating a high thermal conductivity fuel is to start with $\mathrm{UO}_{2}$ and add a second high thermal conductivity material. This second material that is added to the $\mathrm{UO}_{2}$ must be compatible, so it does not react with the $\mathrm{UO}_{2}$ or water, and have a very low neutron absorption cross-section. The composition, orientation, and amount of secondary material are all crucial elements in optimizing the thermal conductivity and structural integrity of the fuel. The objective is to improve the physical properties of the fuel using the minimum amount of secondary material.

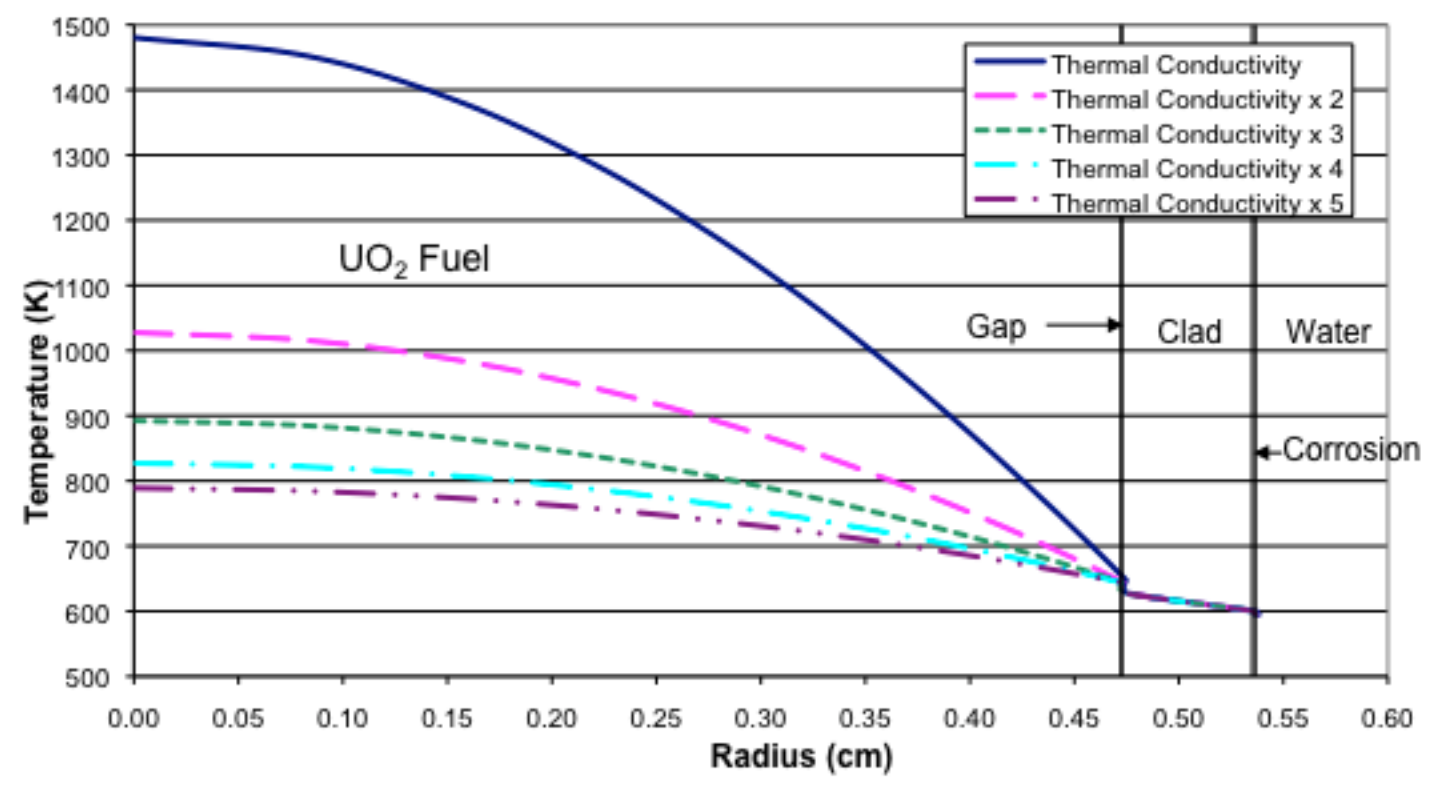

Fig. 2. Radial temperature gradient across a $\mathrm{UO}_{2}$ fuel pin as a function of thermal conductivity.

\subsection{HIGH THERMAL CONDUCTIVITY FIBER BACKGROUND}

One method used to increase the thermal conductivity of $\mathrm{UO}_{2}$ fuel currently being explored at ORNL is the addition of long thin fibers of highly ordered graphite encased within a thin $\mathrm{SiC}$ outer layer. Theoretically, graphite or other types of fibers in $\mathrm{UO}_{2}$ fuel pellets should act as heat conduits, which more efficiently transfer the energy generated deep inside the pellet to the outer edge. Both carbon and silicon have very low absorption cross-sections and have been used in nuclear reactors in the form of coatings on particulate gas-cooled reactor fuel. Amorphous graphite has a thermal conductivity of about $10 \mathrm{~W} / \mathrm{m} \cdot \mathrm{K}$. However, the theoretical thermal conductivity of highly ordered graphite along crystallographic basal planes is more than $2000 \mathrm{~W} / \mathrm{m} \cdot \mathrm{K}$ at room temperature, and $\sim 10 \mathrm{~W} / \mathrm{m} \cdot \mathrm{K}$ perpendicular to the basal planes. ${ }^{4}$ At reactor operating temperatures the planar dimension thermal conductivity drops to $\sim 200$ $\mathrm{W} / \mathrm{m} \cdot \mathrm{K}$ but the transverse dimension thermal conductivity stays fairly constant. $\mathrm{SiC}$ is much more chemically stable than graphite with respect to $\mathrm{UO}_{2}$ but has a lower thermal conductivity and is more susceptible to radiation damage. $\mathrm{SiC}$ coated graphite fiber is a reasonable compromise between high thermal conductivity and chemical compatibility with $\mathrm{UO}_{2}$.

There are concerns associated with compressing and sintering $\mathrm{UO}_{2}$ pellets containing graphite fibers at high temperatures. As the pellet is compressed and sintered the graphite fibers may shatter and disperse or interact with the $\mathrm{UO}_{2}$ forming $\mathrm{CO}_{2}$ and $\mathrm{UC}$ thus destroying the heat transfer pathway. Ideally, to optimize 
thermal conductivity, the fibers need to be intact, should extend from the pellet centerline to the outer edge, have a regular symmetric spacing and be oriented radially perpendicular to the Z-axis. Each of these characteristics will affect the bulk thermal conductivity of the pellet. The problem lies in not knowing the exact form and orientation of the fibers after compression and sintering. Mixing will randomly orient the fibers while uni-axial compression should orient the fibers in a direction more perpendicular to the Z-axis, the axis of compression. In an open system or when combined with $\mathrm{UO}_{\mathrm{x}}$ where $\mathrm{x}>2$ at high temperatures, graphite will combine with the oxygen in $\mathrm{UO}_{2}$ forming $\mathrm{CO}$ or $\mathrm{CO}_{2}$. Currently, $\mathrm{UO}_{2}$ pellets are sintered in a reducing (argon $\left./ 4-6 \% \mathrm{H}_{2}\right)$ atmosphere at temperatures $>1800 \mathrm{~K}$ yielding a pellet having on average 1.98 oxygen atoms per uranium atom. However, within the pellet the oxygen potential will remain high enough that during the reduction to $\mathrm{UO}_{1.98}$ the excess oxygen will oxidize the graphite. The interaction between the $\mathrm{UO}_{2}$ and graphite should be all but eliminated by the thin layer of $\mathrm{SiC}$ on the outer surface of the graphite fiber under processing and operating conditions.

Preliminary computational studies have shown that a substantial increase in the bulk thermal conductivity of low thermally conductive material is possible through the addition of long thin fibers of high thermal conductivity material. Simplified cases consisting of long thin fibers having a length/diameter ratio of 100 were computationally analyzed for different volume percentage of high thermally conducting fibers in a low thermally conducting material. For this study the low thermally conducting material has properties similar to $\mathrm{UO}_{2}$ with its thermal conductivity equal to $3 \mathrm{~W} / \mathrm{m} \cdot \mathrm{K}$. The high thermally conducting material has properties similar to idealized highly ordered graphite with its thermal conductivity ranging from 50 to $500 \mathrm{~W} / \mathrm{m} \cdot \mathrm{K}$ along the axis and $10 \mathrm{~W} / \mathrm{m} \cdot \mathrm{K}$ radially. An additional calculation using Tungsten wire having an isotropic thermal conductivity of $173 \mathrm{~W} / \mathrm{m} \cdot \mathrm{K}$ was also done. Figure 3 below shows how the bulk material thermal conductivity increases with increased fiber volume percent in an idealized system with the fibers perpendicular to the heat transfer surfaces. As shown in Figure 3, a four volume percent addition of highly conducting fibers increases the bulk thermal conductivity of the material by about a factor of 7 for $500 \mathrm{~W} / \mathrm{m} \cdot \mathrm{K}$ fibers; which has the equivalent thermal conductivity of UC or UN fuel without their inherent problems and at a substantially lower manufacturing cost. A 2-4 volume percent addition of $\mathrm{SiC}$ coated graphite fibers on the order of 1 to $5 \mathrm{~mm}$ in length and $10 \mu \mathrm{m}$ in diameter should provide the desired substantial bulk thermal conductivity increase.

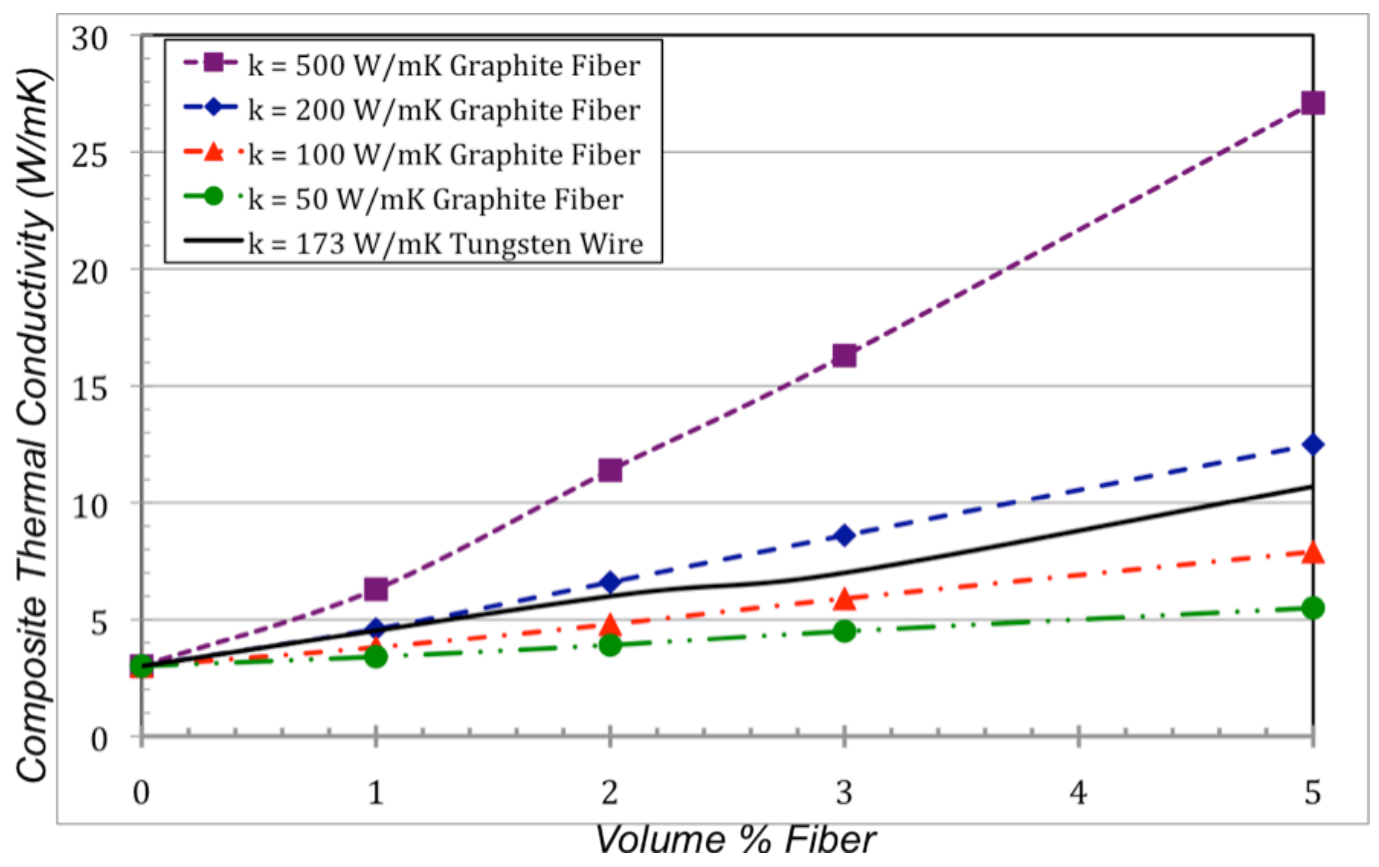

Fig. 3. Increase in thermal conductivity as a function of graphite fiber volume percent. 


\subsection{MICROSTRUCTURAL ENGINEERING BACKGROUND}

The objective of this work is to improve the thermal conductivity and other material properties of $\mathrm{UO}_{2}$ fuel through the introduction of second phase particles to polycrystalline $\mathrm{UO}_{2}$. Fission gases $(\mathrm{Xe}, \mathrm{Kr})$ produced during fission have low solubility in $\mathrm{UO}_{2}$. After a relatively short irradiation period a large number of fission-gas filled bubbles are generated within the fuel grain. The gas atoms in the $\mathrm{UO}_{2}$ migrate to the grain boundaries unless trapped by bubbles. At temperatures where ample grain growth occurs, processes like grain boundary movement can sweep up fission gas atoms more rapidly than they could have arrived at the boundary by diffusion. In addition to providing a heat conduction path the secondary particles can also pin the grain boundaries preventing excessive $\mathrm{UO}_{2}$ grain growth, which stabilizes the material properties and minimizes fission gas release. As the content of the second phase particles increases, a rapid increase in the bulk thermal conductivity occurs at the percolation limit; when the secondary material forms an interconnected path through the material instead of small isolated patches. The resultant increase in thermal conductivity will reduce the thermal gradient in the fuel further minimizing excessive grain growth and reducing fission gas release.

Several different approaches have been taken to increase the overall bulk thermal conductivity of $\mathrm{UO}_{2}$ fuel. One approach involves adding a high conductivity metal to the fuel that provides a continuous heat conduction path; this type of composite material is more commonly known as cermet (ceramic metal). Conventional cermet contains at least $30 \%$ metal in order to provide a continuous metal phase throughout the fuel. ${ }^{5}$ A fabrication process creating a $\mathrm{UO}_{2}-\mathrm{W}$ composite was developed which significantly reduces the amount of metal required. $\mathrm{A} \mathrm{UO}_{2}$-W composite with only 6 vol\% $\mathrm{W}$ was manufactured with an $80 \%$ increase in the thermal diffusivity compared to a standard $\mathrm{UO}_{2}$ pellet. ${ }^{6}$ A major problem with most cermet materials is that the neutronic properties of the metal is not appropriate for use in a nuclear reactor. The metal has a high neutron absorption cross-section thus competing with the uranium, and activates, thus increasing the radioactivity of the spent fuel.

The bulk electrical and thermal conductivity properties of oxide can be improved by the addition of secondary phase particles. Mebane and Gerhardt ${ }^{7}$ have shown that the addition of about $10 \mathrm{vol} . \%$ of a second phase particle increased the electrical conductivity by two orders of magnitude once the percolation limit was reached. Likewise, the thermal conductivity of aluminum oxide ceramics increases with the addition of second phase particles having high thermal conductivity. ${ }^{8}$

Tulenko at the University of Florida has been working on adding $\mathrm{SiC}$ secondary particles to $\mathrm{UO}_{2}$ to increase the bulk thermal conductivity. ${ }^{9}$ Silicon Carbide $(\mathrm{SiC})$ is a potentially good material because of its high thermal conductivity, low neutron absorption cross-section, and relative stability in a radiation field. Several methods of mixing $\mathrm{UO}_{2}$ and $\mathrm{SiC}$ were investigated. Directly mixing $\mathrm{SiC}$ Whiskers and $\mathrm{UO}_{2}$ in a liquid medium was unsuccessful because the $\mathrm{SiC}$, being less dense, tended to stay on top of the $\mathrm{UO}_{2}$. It was necessary to grind the dry $\mathrm{UO}_{2}$ and $\mathrm{SiC}$ together to homogenize the mixture. An attempt was also made to directly coat the $\mathrm{UO}_{2}$ particles with $\mathrm{SiC}$ but his proved unsuccessful due to the polymer precursor being oxidized by the $\mathrm{UO}_{2+\mathrm{x}}$.

The physical properties of both $\mathrm{SiC}$ and Alumina $\left(\mathrm{Al}_{2} \mathrm{O}_{3}\right)$ whiskers make them reasonable candidates as second phase particles added to $\mathrm{UO}_{2}$. Both materials have melting temperatures in excess of $2000^{\circ} \mathrm{C}$, low neutron absorption cross-sections, and are relatively stable when exposed to radiation. Alumina has a relatively stable thermal conductivity of $30 \mathrm{~W} / \mathrm{m} \cdot \mathrm{K}$ over temperature while the thermal conductivity of high purity $\mathrm{SiC}$ peaks at over $400 \mathrm{~W} / \mathrm{m} \cdot \mathrm{K}$ but decreases with temperature as shown in Figure 4 . SiC whiskers have a much lower thermal conductivity, $\sim 50 \mathrm{~W} / \mathrm{m} \cdot \mathrm{K}$, but dramatically decreases above about $1000^{\circ} \mathrm{C}$. 
The objective would be to mix $\mathrm{UO}_{2}$ with second phase particles. The effects of the shape, size and volume content of the second phase particles will be assessed. As noted above, second phases in the form of whiskers having relatively large aspect ratios offer the benefit of a high thermal conductivity along the particle axis. It has been shown that during uniaxial pressing the whiskers rotate the long axis toward the plane normal to the uniaxial pressing axis. This should assist in increasing the radial thermal conductivity of fuel pellets. There are added benefits to fuel pellets aside from an increased thermal conductivity. The whiskers impart to the material increased fracture strength and toughness as well as resistance to thermal shock and creep resistance. ${ }^{11,12}$

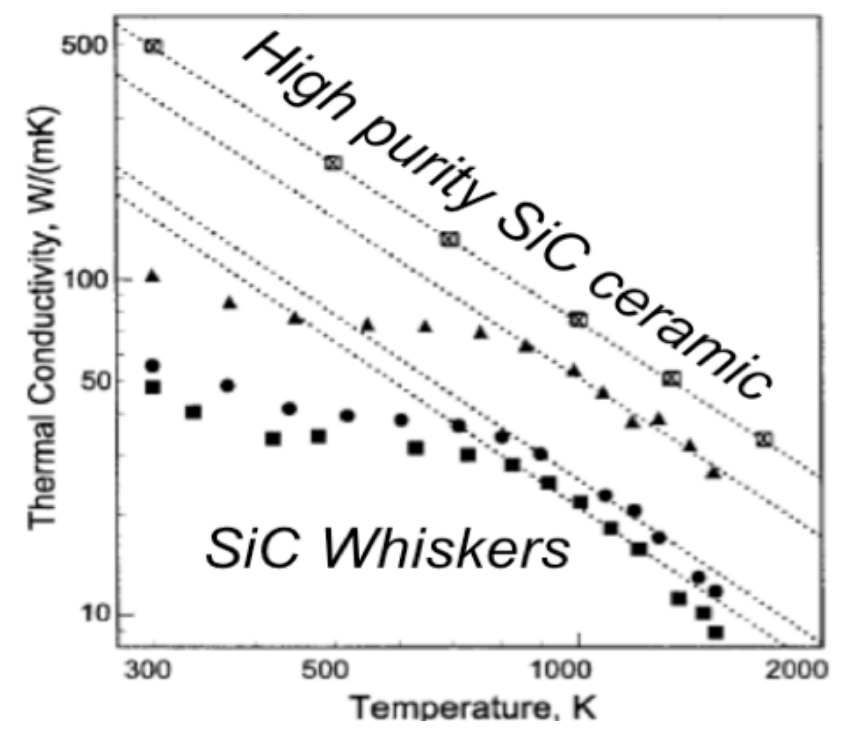

Fig. 4. SiC Thermal Conductivity as function of Temperature. ${ }^{10}$

\section{PROJECT ELEMENTS}

The overall objective of this project is to improve the thermal conductivity and other physical properties of $\mathrm{UO}_{2}$ fuel through the addition of a minimum amount of secondary material. Two separate approaches are being investigated: adding long high thermal conductivity fibers to $\mathrm{UO}_{2}$ prior to pressing and sintering and adding second phase particles/whiskers to the $\mathrm{UO}_{2}$ prior to pressing and sintering. Both approaches will be designed to fit into standard fuel fabrication techniques with minimal changes.

\subsection{TASK 1 - HIGH THERMAL CONDUCTIVITY FIBER TASKS}

This line of research investigates improving the thermal conductivity of $\mathrm{UO}_{2}$ fuel through the addition of high thermal conductivity fibers. In order to simplify the initial phase of the research and development, $\mathrm{CeO}_{2}$ will be used as a surrogate material for $\mathrm{UO}_{2}$. The overall objective of the initial phase is to determine the change in bulk thermal conductivity of a compact as a function of $\mathrm{CeO}_{2}$ grain size, fiber volume percent, fiber length, fiber material, and temperature. The fibers being examined will be composed of two different materials: SiC coated highly ordered graphitic fibers (referred to as graphite fibers) and tungsten fibers. Both fibers have diameters of $\sim 10 \mu \mathrm{m}$ and lengths from $1-5 \mathrm{~mm}$ resulting in an aspect ratio of from 100 to 500 . 
Graphite fibers and tungsten fibers are both being examined because of their vastly different physical properties. The graphite fibers have the best neutronic characteristics of all known high thermal conductivity fibers. They are however brittle, the thermal conductivity changes by an order of magnitude between room temperature and reactor operating temperature, and the physical characteristics of SiC and possibly graphite degrades over time in a neutron radiation field. Tungsten fibers are tough, flexible, do not react with $\mathrm{UO}_{2}$ and have a stable thermal conductivity of $\sim 180 \mathrm{~W} / \mathrm{m} \cdot \mathrm{K}$ over the operating range of a power reactor. However tungsten has unfavorable neutronic properties due to its large neutron absorption cross sections and large resonances.

The approach to protecting the graphitic fibers from oxidation during sintering and irradiation involves having a thin $\mathrm{SiC}$ layer on the outer surface of the fibers. A successful approach recently demonstrated at ORNL siliconizes the graphite fiber outer surface. A gas mixture of $\mathrm{Ar}-4 \% \mathrm{SiH}_{4}$ flows through a bed of fibers in a reaction chamber at elevated temperature. Elemental silicon deposits on the fibers, with some interaction/carbide formation. In order to have sufficient reaction to form a $\mathrm{SiC}$ layer on the surface of the fibers a post-deposition heat treatment is performed under inert gas. Electron microscopy of the product fibers, see Fig. 5, indicate sufficient $\mathrm{SiC}$ surface material on the fibers that is adherent and coherent, yet a large majority of the diameter remains solely carbon as desired.

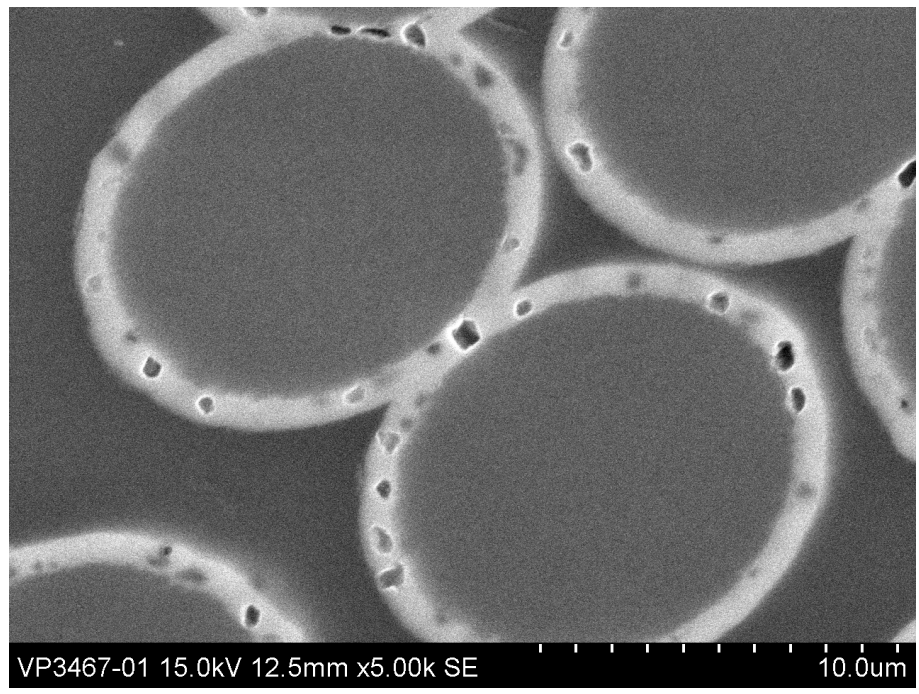

Fig. 5. Micrograph of SiC coated graphite fibers.

Different compact fabrication techniques are being developed that take advantage of the different fiber characteristics. The flexibility of the tungsten fibers means they will not shatter when exposed to excessive forces as happens with graphite fibers. However, the tungsten fibers tend to entangle into a single mass when mixed with $\mathrm{CeO}_{2}$ particles in a blender. Due to the tendency of the tungsten to entangle and the brittle nature of the graphite fibers, a mixing and processing method that imparts minimal shear forces on them is required. If the mixing is too aggressive the graphite fibers will break into smaller pieces and expose carbon surfaces. Dispersants are used in liquid suspensions of oxide and fibers to form a homogeneous mixture; which are then dried. The dried powder/fiber mixture is then isostatically pressed to form a green pellet of at least $50 \%$ theoretical density. The compact is then sintered in a controlled atmosphere to produce a pellet with the desired density, generally $\geq 95 \%$ theoretical density (TD).

The thermal conductivity of each compact will be determined using Laser Flash Thermal Diffusivity over the range of temperatures from $20-1000^{\circ} \mathrm{C}$. The technique works by applying a short laser pulse at one 
side of a compact and measuring the time it takes for the heat to travel through the compact to the other side. Using the time needed to reach $50 \%$ of maximum temperature and the sample thickness a diffusivity coefficient can be calculated. Using the diffusivity coefficient, the material density and heat capacity the bulk thermal conductivity can be determined. Even in the absence of known heat capacity, comparative thermal diffusivities will provide the necessary guidance.

Concurrent with the manufacturing and testing of the $\mathrm{CeO}_{2}$-fiber compacts, computer simulations will be conducted with the intent to calculate the bulk thermal conductivity using various amounts and sizes of graphite and tungsten fibers in compacts. ORNL researchers have developed the capability, based on finite element analysis (FEA), to calculationally evaluate the bulk material properties, such as thermal conductivity, of composites composed of multiple materials having different properties. ${ }^{13}$ These computer simulations will be used to assist in the selection of fiber dimensions and amounts to be mixed with the $\mathrm{CeO}_{2}$ powder to create the compacts. Optical micrographs of the compacts will be created to physically examine the final structure of the fibers in the compacts. These will be used as input to the computer codes to benchmark the analytical techniques and help determine other fiber dimensions and concentrations to be used in compacts.

When sufficient progress has been made using $\mathrm{CeO}_{2}$, work will begin using $\mathrm{UO}_{2}$. The types and volume percents of fibers should be very similar to those determined using $\mathrm{CeO}_{2}$. Likewise, the mixing and sintering techniques developed should also be directly applicable. The primary work will involve adjusting the chemistry parameters such as binding and dispersant agents and concentrations. After $\mathrm{UO}_{2} /$ fiber compacts have been manufactured, detailed chemical and physical analyses of the compacts will be performed. Laser Flash Thermal Diffusivity measurements of the compacts ranging from $20^{\circ} \mathrm{C}$ to $1000^{\circ} \mathrm{C}$ will be performed. Mechanical properties of the compacts such as toughness and strength will be assessed. Scanning Electron Microscopy (SEM) will be used to ensure the fibers are properly distributed in the compacts. Other physical properties of the compacts will be fully assessed and compared to standard $\mathrm{UO}_{2}$ fuel prior to the next step.

Once the physical characteristics of the compacts are fully understood and found to be acceptable, test rods will be manufactured and placed in the High Flux Isotope Reactor (HFIR) for full power irradiation testing. ORNL has developed a test assembly for HFIR that approximates a standard PWR's power and neutron flux profile. ${ }^{14}$ Temperature and pressure sensors in the fuel pin will continuously monitor the pellet internal centerline temperatures and gas pressure as the fuel pin is irradiated. At regular intervals individual fuel rods will be removed and post-irradiation examination (PIE) will be performed. The biggest unknowns are the effects of the radiation on the pellet's physical properties as the fuel burns. Questions that will be addressed in the irradiation/power testing phase include but are not limited to: will the damage from the radiation and neutron absorption change the thermal conductivity, how is fission gas release affected, what is the effect on pellet clad interaction, and how is pellet swelling affected.

The end result of this research is to develop a $\mathrm{UO}_{2}$ fuel pellet that has superior physical properties to standard $\mathrm{UO}_{2}$ pellets and can retain those properties for much higher burnups and power densities. For this to work the high thermal conductivity fiber needs to retain its properties for the length of time the fuel is in the reactor and be neutronically benign. Below is a summary of the necessary procedures to complete this research and bring it to a level where it can be used in industry. 
1. A technique for adding a $\mathrm{SiC}$ outer layer to graphite fibers has already been developed at ORNL involving passing $\mathrm{Ar}-4 \% \mathrm{SiH}_{4}$ (silane) gas over graphite fibers at elevated temperature

a) Manufacture additional $\mathrm{SiC}$ coated graphite fibers using the techniques developed

2. ORNL has obtained several spools of $99.9 \%$ pure $10 \mu \mathrm{m}$ diameter tungsten wire

a) Cut the tungsten wire into lengths ranging from 1 to $5 \mathrm{~mm}$

3. Create $\mathrm{CeO}_{2} /$ fiber ( $\mathrm{SiC}$ coated graphite or tungsten) compacts using ceramic processing techniques

a) Examine different binding agents and concentrations

b) Examine different dispersant agents and concentrations

c) Vary fiber volume percent and lengths

4. Sinter the compacts at $1700^{\circ} \mathrm{C}$ to $95 \% \mathrm{TD}$

a) SEM and optical micrographs

5. Measure thermal diffusivity/conductivity $(k)$ of the compacts using laser flash thermal diffusivity:

a) Perform measurement at room temperature

b) Perform measurement at elevated temperatures to up to $1000^{\circ} \mathrm{C}$

6. Perform computer simulations of thermal conductivity $(k)$ at various fiber content

7. Repeat steps 3,4 and 5 using $\mathrm{UO}_{2}$ in place of $\mathrm{CeO}_{2}$

8. Manufacture fuel pellets and an instrumented test assembly for HFIR

9. Place test assembly in HFIR for radiation/power tests

10. Periodically remove fuel rods for PIE

\subsection{TASK 2 - MICROSCTRUCTURAL ENGINEERING TASKS}

This line of research investigates improving the thermal conductivity and other physical properties of $\mathrm{UO}_{2}$ fuel through the addition of second phase particulates. Evaluations will include the restraint of grain growth and the immobilization of solid fission product inclusions through pinning of grain boundaries by second phase particles. In order to simplify the initial phase of the research and development, $\mathrm{CeO}_{2}$ will be used as a surrogate material for $\mathrm{UO}_{2}$. The overall objective of the initial phase is to determine the change in bulk thermal conductivity and other physical properties of a compact as a function of $\mathrm{CeO}_{2}$ grain size; second phase particle type, grain size, and volume fraction; and percolation limit.

Initial studies employing $\mathrm{CeO}_{2}$ as the matrix (also fluorite structure with melting point $2400^{\circ} \mathrm{C}$ somewhat lower than $\mathrm{UO}_{2} 2865^{\circ} \mathrm{C}$ ) will examine the effects of second phase particle size and volume fraction on the microstructural stability. With the knowledge gained in these studies, similar studies will combine microstructural stability with increased thermal conductivity with the addition of a high thermal conductivity second phase (e.g., $\mathrm{BeO} 280-300 \mathrm{~W} / \mathrm{m} \cdot \mathrm{K}$ or SiC particles $(\sim 400 \mathrm{~W} / \mathrm{m} \cdot \mathrm{K})$ or whiskers $(\sim 50$ $\mathrm{W} / \mathrm{m} \cdot \mathrm{K})$. The percolation limit (i.e., the amount of second phase needed to increase thermal conductivity) will be established as a function of volume content and size of the second phase material through modeling and experimental studies. Laser Flash Thermal Diffusivity measurements of the compacts ranging from $20^{\circ} \mathrm{C}$ temperature to $1000^{\circ} \mathrm{C}$ will be performed.

Computer simulations will be conducted with the intent to calculate the bulk thermal conductivity, fracture strength, toughness, and creep resistance using various amounts and types of second phase particles. ORNL has developed the capability, based on finite element analysis (FEA), to calculationally evaluate the bulk material properties, such as thermal conductivity, of composites composed of multiple materials having different properties. ${ }^{13}$ These computer simulations will be used to assist in the selection of second phase particle type and amounts to be mixed with the $\mathrm{CeO}_{2}$ powder to create the compacts. Optical micrographs of the compacts will be created to physically examine the final structure of the compacts. These will be used as input to the computer codes to benchmark the analytical techniques and help determine the composition of future compacts. 
A critical element in the effectiveness of high thermal conductivity additions (fibers, whiskers or particles) is that of the interfacial thermal resistance, which dictates whether or not one achieves any improvement in the thermal conductivity in the resultant composite. The interfacial resistance can result from several factors, e.g., non-intimate contact between the matrix and the second phase (fiber, whisker or particle), or accumulation of segregating species (impurities, additives) at the interfaces. In essence, the interfacial thermal resistance can negate any contribution of the high conductivity phase. For instance in Aluminum Nitride (AIN), sintering additives and the grain size can alter the thermal resistance of grain boundaries and hence, the overall thermal conductivity of the ceramic; high thermal conductivity is achieved by eliminating segregation at grain boundaries. ${ }^{15,16}$ Recent results with $\mathrm{SiC}$ whisker reinforced alumina composites reveal that a combination of $\mathrm{MgO}$ and $\mathrm{Y}_{2} \mathrm{O}_{3}$ sintering additives produce temperaturedependent thermal conductivities that are essentially the same as that of a dense alumina ceramic. Both $\mathrm{MgO}$ and $\mathrm{Y}_{2} \mathrm{O}_{3}$ have extremely limited solubility in alumina; thus, they typically will tend to reside at grain or whisker interfaces. In the absence of additives, the conductivity increases with content of $\mathrm{SiC}$ whiskers. ${ }^{17}$ The results of second phase particle characteristics can also have an affect. ${ }^{10,18}$ Differences in thermal expansion coefficients between matrix and second phase additions can alter the contact between them. The expansion coefficient of $\mathrm{UO}_{2}$ is about twice as large as that of SiC. The interface characteristics (e.g., continuity, chemistry and thermal resistance) will be characterized using various techniques (e.g., Scanning Transmission and Transmission Electron Microscopy combined with chemical analysis to detect interfacial segregation and/or interfacial films, and Scanning Probe Microscopy thermal characterization ${ }^{19}$ to measure thermal transport.

When sufficient progress has been made using $\mathrm{CeO}_{2}$, work will begin using $\mathrm{UO}_{2}$. The types and volume fractions of second phase particles should be very similar to those determined using $\mathrm{CeO}_{2}$. Likewise, the mixing and sintering techniques developed should also be directly applicable. After compacts have been manufactured detailed chemical and physical analyses of the compacts will be performed. Flash Laser Diffusivity measurements of the compacts ranging from $20^{\circ} \mathrm{C}$ to $1000^{\circ} \mathrm{C}$ will be performed. Mechanicalproperties of the compacts such as toughness and strength will be assessed to ensure the second phase particle/ $\mathrm{UO}_{2}$ matrix is stable. SEM will be used to examine the distribution of second phase particles in the compacts. The physical properties of the compacts will be fully assessed and compared to standard $\mathrm{UO}_{2}$ fuel prior to the next step.

Once the physical characteristics of the compacts are fully understood and found to be acceptable, fully instrumented test rods will be manufactured and placed in HFIR for full power irradiation testing. ORNL has developed a test assembly for HFIR that approximates a standard PWR's power and neutron flux profile. Temperature and pressure sensors in the fuel will continuously monitor the pellet internal centerline temperatures and gas pressure as the fuel pins are irradiated. At regular intervals individual fuel rods will be removed and PIE will be performed. The biggest unknowns are the effects of the irradiation on the pellet's physical properties as the fuel burns. Questions that will be addressed in the irradiation testing phase include but are not limited to: will the damage from the radiation and neutron absorption change the thermal conductivity of the compacts, how is fission gas release affected, what is the effect on pellet clad interaction, and how is pellet swelling affected.

The end result of this research is to develop a $\mathrm{UO}_{2}$ fuel pellet that has superior physical properties to standard $\mathrm{UO}_{2}$ pellets and can retain those properties for much higher burnups and power densities. For this to work the compacts need to retain their properties for the length of time the fuel is in the reactor and be neutronically benign. Below is a summary of the necessary procedures to complete this research and bring it to a level where it can be used in industry. 
1. Assess properties of existing $\mathrm{UO}_{2} / \mathrm{Al}_{2} \mathrm{O}_{3}$ compacts existing at $\mathrm{ORNL}$

a) Thermal Conductivity

b) Fracture Strength and Toughness

c) Thermal Shock and Cyclic Fatigue

d) Creep Resistance

2. Create $\mathrm{CeO}_{2}$ / second phase particle compacts

a) $\mathrm{Al}_{2} \mathrm{O}_{3}, \mathrm{SiC}, \mathrm{BeO}$ at different concentrations

b) Examine physical properties (SEM, ceramotography, optical micrographs, etc.)

c) Establish percolation limits

3. Measure thermal diffusivity/conductivity $(k)$ of the compacts using laser flash diffusivity:

a) Perform measurement at room temperature

b) Perform measurement at elevated temperatures to at least $1000^{\circ} \mathrm{C}$

4. Perform computer simulations of thermal conductivity $(k)$, fracture strength and toughness for selected second phase particle compacts

5. Repeat steps 2 and 3 using $\mathrm{UO}_{2}$ in place of $\mathrm{CeO}_{2}$

6. Manufacture fuel pellets and an instrumented test assembly for HFIR

7. Place test assembly in HFIR for irradiation tests simulating as close as possible LWR burnup, fluence, and neutron energy spectrum

8. Periodically remove fuel rods for PIE

\section{PROJECT SCHEDULE AND COST}

The budget proposed extends over three fiscal years and sums to a total of just over $\$ 5,000,000$. There are two distinct approaches to the development of the new fuel: compacts composed of $\mathrm{UO}_{2}$ and high thermal conductivity fibers (ETC) and compacts composed of $\mathrm{UO}_{2}$ and second phase particles (ME). The cost of each line of research is independent up to the manufacture of the pellets that will be used as test fuel. At this point the total cost of writing the safety analysis report; manufacturing the fuel/test rodlets; inserting, monitoring, retrieving and examining the fuel in the test assemblies is dependent on the number of test articles. Table 1 provides an overview of the project cost; Figure 6 provides the high level schedule. Assuming acceptable fuel compacts can be manufactured and placed in HFIR as part of an instrumented test assembly, further funding would be required for extended monitoring and PIE to further contribute to fuel qualification efforts. 
Table 1. Overview of Cost and Work Schedule

\begin{tabular}{|c|c|c|c|c|c|}
\hline \multicolumn{2}{|l|}{2011} & \multicolumn{2}{|l|}{2012} & \multicolumn{2}{|l|}{2013} \\
\hline Task & $\begin{array}{c}\text { Cost } \\
(\$ 1000)\end{array}$ & Task & $\begin{array}{c}\text { Cost } \\
(\$ 1,000)\end{array}$ & Task & $\begin{array}{c}\text { Cost } \\
(\$ 1,000)\end{array}$ \\
\hline $\begin{array}{l}\text { Project Management, } \\
\text { Quality Assurance, } \\
\text { and Travel }\end{array}$ & 158 & $\begin{array}{l}\text { Project Management, } \\
\text { Quality Assurance, and } \\
\text { Travel }\end{array}$ & 158 & $\begin{array}{l}\text { Project } \\
\text { Management, } \\
\text { Quality Assurance, } \\
\text { and Travel }\end{array}$ & 158 \\
\hline $\begin{array}{l}\text { ETC - Develop } \mathrm{CeO}_{2} \\
\text { Compacts }\end{array}$ & 500 & $\begin{array}{l}\text { ETC - Fuel Pellet } \\
\text { Production }\end{array}$ & 400 & $\begin{array}{l}\text { Irradiate Rodlets in } \\
\text { HFIR }\end{array}$ & 100 \\
\hline $\begin{array}{l}\text { ETC - Compute } \\
\text { Simulations }\end{array}$ & 100 & $\begin{array}{l}\text { ME - Fuel Pellet } \\
\text { Production } \\
\end{array}$ & 400 & $\begin{array}{l}\text { Monitor Test } \\
\text { Irradiation in HFIR }\end{array}$ & 300 \\
\hline $\begin{array}{l}\text { ETC - Develop } \mathrm{UO}_{2} \\
\text { Compacts }\end{array}$ & 300 & \begin{tabular}{|l|} 
Design Instrumented \\
Irradiation Facility \\
\end{tabular} & 750 & & \\
\hline $\begin{array}{l}\text { ME - Assess existing } \\
\mathrm{SiC}-\mathrm{Al}_{2} \mathrm{O}_{3} \text { compacts }\end{array}$ & 200 & $\begin{array}{l}\text { Fabricate Rodlets and } \\
\text { HFIR Instrumented } \\
\text { Irradiation Facility }\end{array}$ & 750 & & \\
\hline $\begin{array}{l}\mathrm{ME}-\text { Create } \mathrm{CeO}_{2} / 2^{\text {nd }} \\
\text { phase particle } \\
\text { compacts }\end{array}$ & 500 & $\begin{array}{l}\text { Prepare USQD \& } \\
\text { EABD for HFIR Test } \\
\text { Irradiation }\end{array}$ & 200 & & \\
\hline $\begin{array}{l}\text { ME - Compute } \\
\text { Simulations }\end{array}$ & 100 & & & & \\
\hline $\begin{array}{l}\mathrm{ME} \text { - Develop } \mathrm{UO}_{2} \\
\text { Compacts }\end{array}$ & 300 & & & & \\
\hline Total & $\$ 2,158$ & & $\$ 2,658$ & & $\$ 558$ \\
\hline
\end{tabular}

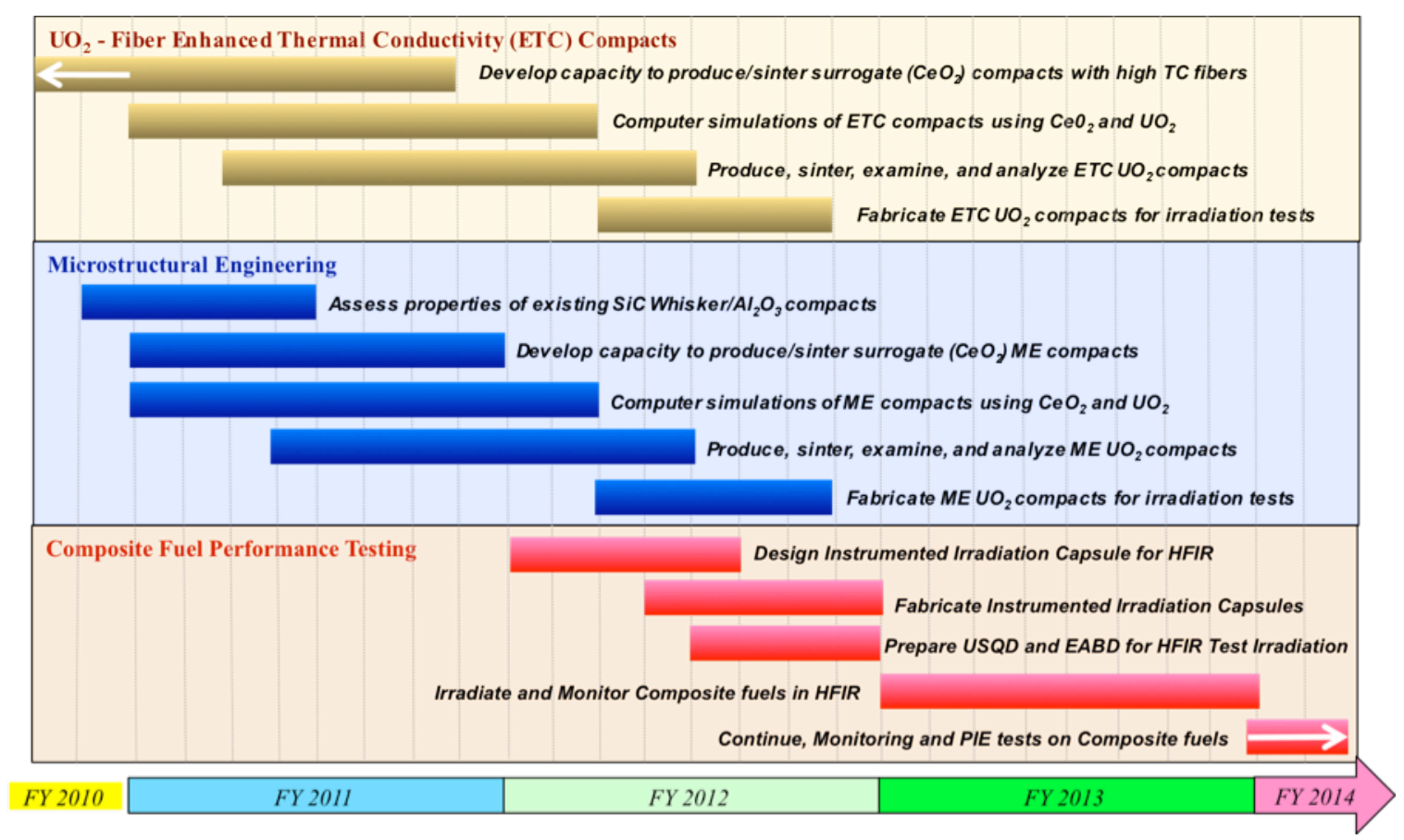

Fig. 6. High level work Schedule. 


\section{REFERENCES}

1. D. Lanning, C. Beyer, and K. Geelhood, FRAPCON-3 Updates, Including Mixed-Oxide Fuel Properties, NUREG/CR-6534, Vol. 4, May 2005.

2. H. Matzke, Science of Advanced LMFBR Fuels, North-Holland, Amsterdam, 1986.

3. R. Cahn, P. Haasen and E. Kramer (Eds.), Materials Science and Technology, Volume 10A, Chapter 4,VCH Publishers Inc., New York, 1994.

4. B. T. Kelly, Physics of Graphite, Applied Science Publishers, London (1981).

5. K. Bakker, F.C. Klaassenn, et. al., Nuc. Technol., 146 (2004) 325.

6. Jae Ho Yang, Kun Woo song, Keon Sik Kim and Youn Ho Jung, "A fabrication technique for a $\mathrm{UO}_{2}$ pellet consisting of $\mathrm{UO}_{2}$ grains and a continuous $\mathrm{W}$ channel on the grain boundary," Journal of Nuclear Materials 353 (2006) 202-208.

7. D. S. Mebane and R. A. Gerhardt, J. Am. Ceram. Soc. 89[2] 538-43 (2006).

8. P. H. McClusky, R. K. Williams, R. S. Groves and T.N. Tiegs, "Thermal Diffusivity/Conductivity of Alumina-Silicon Carbide Composites," J. Am. Ceram. Soc. 73[2] 461-64 (1990).

9. K.S. Tulenko and R. H. Baney, "An Innovative High Thermal Conductivity Fuel Design," DOE F2413, U.S. Department of Energy (2007).

10. M.I.K. Collin and D. J. Rowcliffe, J. Am. Ceram. Soc. 84[6] 1334-40 (2001)

11. P.F. Becher, J. Am. Ceram. Soc. (1991)

12. H.T. Lin and P.F. Becher, J. Am. Ceram. Soc. (1991)

13. W. J. Parker, R. J. Jenkins, C. P. Butler and G. L. Abbott, "Flash Method of Determining Thermal Diffusivity, Heat Capacity, and Thermal Conductivity," Journal of Applied Physics, 32:1679-1684 (1961).

14. L. J. Ott, B. B. Bevard, R. J. Ellis, J. L. McDuffee, D. J. Spellman, “Advanced Fuel/Cladding Testing Capabilities in the ORNL High Flux Isotope Reactor," Proc. Of Top Fuel (2009) 815-822 3093-95 (2002).

15. Hiromi Nakano, Koji Watari, Hiroyuki Hayashi, and Kazuyori Urabe, J. Am. Ceram. Soc., 85 [12] 3093-95 (2002).

16. YASUHIRO KUROKAWA, KAZUAKI UTSUMI, and HIDE0 TAKAMIZAWA, J. Am. Cernm. Sor., 71171 588-94 (1988).

17. P. H. McCluskey, R. K. Williams, R. S. Graves and T. N. Tiegs, J. Am. Ceram. Soc., 73[2]461-64 (1990).

18. L.M. Russell, L. F. Johnson and D. P. H. Hasselman, J. Am. Ceram. Soc., 70[10] C-226-29 (1987).

19. J.-H. Lee1 and Y. B. Gianchandani, Rev. Sci. Instrum. 75, 1222 (2004). 